Dialectic Volume I, Issue I: Front Matter

\title{
Journaling through the Back Door
}

STEVEN MCCARTHY ${ }^{1}$

1. Professor Graphic Design Program, University of Minnesota

SUGGESTED CITATION: McCarthy, S. “Journaling Through the Back Door.” Dialectic, 1.1 (2016): pgs. 10-13. DOI: http://dx.doi. org/10.3998/dialectic.14932326.0001.102 
Journaling

through

the Back

Door

STEVEN MCCARTHY

For the first third of my academic career, roughly the 1990s, I taught undergraduate graphic design in a university art department; I maintained a fledging professional practice (with clients mostly in the arts and publishing); and I made speculative, self-authored works - primarily artist's books. The job emphasis was clearly on classroom teaching - the load was three courses per semester - but the occasional exhibit, publication, or competition that I got into built self- esteem and was appreciated by my students, colleagues and superiors.

When I joined the faculty at the University of Minnesota eighteen years ago, my job took a 'research turn' as I now teach two courses per term, advise graduate students, and am expected to produce significant scholarship. I was the first tenure-track hire with an MFA in the Department of Design, Housing, and Apparel (with programs in interior, apparel, product and graphic design, plus housing studies and retail merchandising). Most of my new colleagues, including those teaching graphic design, had PhDs. My colleagues tend to define themselves intellectually as social scientists, engineers and humanists, with few design practitioners and artists among them.

I had departed a culture that valued individual artistic expression, studio production, professional practice and exhibitions and joined one that privileged qualitative and quantitative research methods, collaboration, interdisciplinarity and peerreviewed publishing. I had to quickly adapt to this new culture and I had to educate my colleagues about other ways that design faculty could create scholarship. The Department's tenure and promotion guidelines acknowledged the parity of juried exhibits to journal publishing, but the culture maintained a pecking order, and journal publishing ruled.

\section{Since then, here is what I have learned about journal publishing.}

Publishing in academic journals, while daunting to consider initially, is not that difficult. Unlike most design competitions and art exhibits, which give a straight 'thumbs up' or 'thumbs down' judgment, the peer review process means that submitters receive the critical commentary of others to better shape their writing and research. Unless rejected outright, manuscripts can be revised and resubmitted. In my personal experience, the odds of journal acceptance are more likely than that of juried exhibition or design competition acceptance.

There are plenty of design journals, representing diverse design ideologies, interests, theories, critical discourses and so on. Finding a venue for publishing one's writing is made easier when the scholar directs their efforts towards a journal that - through the topics covered, its mission statement, the composition of its editorial board, or its theme-based call for submissions - seems to be a good fit for the paper. And because many international academic journals are published in English, there are ample calls for papers from journals published abroad. 
Trade magazines are not academic journals. While design journalism is a legitimate pursuit (I've written a number of essays for Eye), unless the reviewers are peers (typically, advanced degree-holders) and unless the process is blind (anonymity between author and reviewer), the interests of most commercial magazines are not to create new knowledge for the discipline through research. Those magazines that host annual design competitions have found a profitable way to showcase professional practice that has more to do with entry fees and advertisements than critical discourse. That said, it would be a welcome convergence if the rigor of journal publishing were matched by the broad readership of design magazines and websites.

Not all journals are equal. Some have higher prestige; some have more selective acceptance rates; some have longer histories; some are published by notable university presses; and some have the institutional support of a major organization. The only effort l'm aware of to rank design journals has been by Ken Friedman, et al., in Design Research Journal Ranking Study: Preliminary Results (2008). Since then, Ico-D's new journal Communication Design, Interdisciplinary and Graphic Design Research and AIGA's Dialectic have been launched. How will these newcomers fit in to the reputations earned by Design Issues, Visible Language, Design and Culture, Visual Communication, Design Studies, The Poster, The Design Journal, Book 2.0 and numerous others?

Journal publishing takes time. The typical cycle of research, writing, submitting, revising, resubmitting, editing and publishing can take the better part of a year. (I had one paper take five years from manuscript to print!) This means that tenure track design faculty need to have multiple 'irons in the fire' annually to be productive. One thing that ought to be revisited is the convention in academic publishing that manuscripts can only be under review at one journal at a time; this is in the best interest of the journal but to the detriment of the scholar. Clearly, publishing in two journals simultaneously should be forbidden, but why shouldn't a scholar have their paper published in the first journal that gives them the 'thumbs up'? This would add an element of competition to peer turn-around, and incentivize timely responses.

One doesn't need a PhD to publish in journals. Using effective research methods, the ability to think critically, good writing skills, and command of the subject matter are strengths of many design faculty with other advanced degrees. Mastering the style guides required for specific publications (APA, MLA, Harvard, etc.) can be a minor challenge, but getting the citations right lends credibility to one's argument.

\section{Here is what I hope I have taught my departmental colleagues.}

Scholarship in graphic design can take many forms, and can be disseminated in myriad venues. Juried and invitational exhibits, media festivals, performances, presentations, curatorial projects, entrepreneurial ventures, institutional collections, and more, are viable and appropriate for graphic design. Like journal articles, the design (image, product, experience, service, tool, environment, etc.) should undergo peer review to qualify as scholarship. Even the magazine competitions that I criticized earlier have an acceptance rate of around 5\% (perhaps for economic reasons), which is highly competitive, and depending on the nature of the faculty member's creative practice, a potentially appropriate venue.

Graphic design has another quality that makes it well-suited for making scholarly inquiry manifest: it is self-exemplifying. The ability of graphic design to add meaning to content through visual form should not be overlooked. The typefaces, images, layouts, colors, patterns, paper choices, printing techniques, binding structures and so on that contribute to visual, spatial and tactile form serve to amplify, clarify, dramatize or add critical commentary to texts. The same applies to screen-based content, with design features like animation, navigation, sound and other interactive qualities. 
Graphic design journals must be well-designed; anything less is hypocritical. Zed, a visually sophisticated journal published seven times by Virginia Commonwealth University in the 1990s, understood this. Visible Language's recent website overhaul presents an archive of its articles in an intelligent and handsome manner.

My department now considers what might be termed an 'inclusive scholarship life-cycle': faculty effort, scholarly product, the selection process, the dissemination venue, and the resulting impact. For example, using this sequence: research and writing/a paper/that is blind peer-reviewed/and published in a journal/that was cited by other scholars. This same model can apply to graphic design: creating/a design/ that is juried/into an exhibition/and acquisitioned into a museum's permanent collection. Considerations like rigor, scope, quality, originality and authorial role pertain equally to judging the merits of both outcomes.

I'll conclude with this statement by Meredith Davis, North Carolina State University professor emerita: “There are many paradigms for design research and it is the obligation of institutions to sort out where they stand on these issues. 'Smart' is not the opposite of 'beautiful.' Knowledge does not undermine creativity." (2016)

Graphic design scholarship is uniquely positioned to combine, and challenge, knowledge with creativity hence the dialectic.

\section{References}

Friedman, K., Barron, D., Ferlazzo, S., Ivanka, T., Melles, G. and Yuille, J. (2008) Design Research Journal Ranking Study: Preliminary Results. http://researchbank.swinburne.edu.au/vital/ access/manager/Repository/swin:10413 (online 28 May 2016)

Davis, M. (2016) Tenure and Design Research: A Disappointingly Familiar Discussion. Design and Culture, the Journal of the Design Studies Forum. Routledge. 8:1, 123-131. 